\title{
Immunity or morphogenesis in cancer development and treatment
}

\author{
Shoutko AN* \\ Laboratory for Improvement of the Cancer Treatment Methods, Russian Granov's Research Center for Radiology and Surgical Technologies, Ministry of Health \\ Care of the Russian Federation, Russia
}

\begin{abstract}
Non-selective cytotoxic therapy of cancer is effective, acting harmfully for a host. Legal deep lymphocytopenia at conventional cytotoxic therapy, high risk of new malignancies after it, spreading of malignant cells through favorite lymph nodes, a restriction of immunocytes activity inside tumor at anti-angiogenic treatment does not feet the idea of host immune defense against spontaneous cancer. To understand these theoretical inconsistencies we discussed the development of a tumor and its microvessels, gradual exhaustion of hematopoietic stem cell number in blood and arising of cancer cachexia, ratio of infectious morbidity and cancer mortality in their interrelation, using an experimental, clinical data and population statistics. We concluded, that mentioned above and other principal discrepancies would become regularities, if the cells renewing in both malignant and normal tissues were taken as a result of the recently discovered morphogenesis activity of circulating mononuclear cells, originated from the bone marrow and presented by tissue's committed stem cells and some subsets of morpho-angiogenic lymphocytes.
\end{abstract}

\section{Introduction}

Invariable difficulties in rejection of a tumor and retention of an allograft exist in the theoretical sphere of cellular immunity, where these two tasks are united. The strategy of immunotherapy demands to reduce of regulatory T cells- "suppressors" in cases of cancer, but extend them in case of allograft [1]. It is not clear, why such opposite immune reactions expected, if both malignant tissue and allograft, in the case being non-self, can provoke a uniform anti-allogeneic response. It is not clear also, why the practice of therapy both of cases leads to a uniform lymphocytopenia. Similarly, why the age-related decline in immunity associates with decreased survival of recipients of the liver allograft [2], but follows by improvement of mortality, incidence, and prevalence of malignancy among old cancer patients [3]. The "favorite" paths of the tumor cells dissemination, namely blood, and lymph nodes, are the very location of supposed "protective" cells. The modern anti-angiogenic therapy [4,5] prevents circulating lymphocytes interaction with tumor cells. The idea of non-selective cytotoxic therapy as the stimulator of immune defense against tumor dominates despite the main antineoplastic agents are carcinogenic, toxic, mutagenic, clastogenic, teratogenic [6] and treated cancer survivors have increasing risk of developing new malignancies by $14 \%$ compared with the general population [7]. The idea for tumor deception of immune protection is popular, in spite of the lowest limit of lymphocytopenia permitted at cancer therapy [8] and this level is comparable with such for survivors after nuclear bombing [9].

Alternatively, multi-annual practice [8] assumes that lymphocytopenia, induced by anti-cancer therapy, relates somehow to a positive result. Some scientists concluded earlier that mononuclear cells have the global morphogenesis function because they transfer regenerative information to purpose-oriented normal and malignant tissues on the distributive base [10-19]. However, overly pedantic belief towards the existence of the anti-neoplastic immunity did not cause comprehensive public discussion of the idea of spontaneous tumors belonging to tissues, which do not provoke any protective reactions of the host [20-23].

At present, the new facts of involvement of hematopoietic stem cells into tissues regeneration challenge again the traditional interpretation of lymphocytopenia, induced by cancer therapy, as annoying adverse effect or side effect. Its role continues to be far from well-defined and demands the reconsideration. We attempt to fill this gap using data for morphogenesis properties of primitive cells of the hematopoietic system, which were not known 20-30 years ago and should not be ignored further in palliative treatment of cancer. The experimental and clinical data, including population statistics for cancer patient's vitality, will be considered as the most reliable criterion to prove the practical significance of morphogenesis function of circulating hematopoietic stem cells and lymphocytes.

The following data illustrates the involvement of specific circulating mononuclear cells in the nutrient supply and development of both the normal and malignant tissues.

\section{Haematopoiesis and tissues function}

\section{Haematopoiesis and normal tissues}

Most of the primitive mononuclear cells in the bone marrow and blood of adults represented by markers CD133+CD34-, $\mathrm{CD} 133+\mathrm{CD} 34+, \mathrm{CD} 133-\mathrm{CD} 34+$, and marker CD133 is ancestral to

${ }^{\star}$ Correspondence to: Shoutko AN, Laboratory for Improvement of the Cancer Treatment Methods, Russian Granov's Research Center for Radiology and Surgical Technologies, Ministry of Health Care of the Russian Federation, SaintPetersburg, Russia, E-mail: shoutko@inbox.ru

Key words: morphogenesis, limphocytopenia, lymphocytes, hematopoietic stem cells, cancer, cytotoxic therapy, competitive therapy, side effects

Received: July 29, 2019; Accepted: August 14, 2019; Published: August 17, 2019 
CD34. Strongly proliferating CD133+ cells are able to differentiate into cells with characteristics of mesoderm, endoderm and neuroderm layers: endothelial progenitor cells, neural progenitor-like cells, astrocytes, oligodendrocytes, cells of kidney proximal tubules, cells of lactiferous ducts of the mammary gland, cells of the prostate gland, skin, lung, intestine, hepatocyte-like cells and skeletal muscle-like cells, expressed primary tissue- associated proteins $[13,24]$. The primitive cells of bone marrow migrate through the blood into different tissues and organs, especially after their injury [25]. The many examples of enhancing nonmalignant tissue regeneration via primitive bone marrow cells stimulation or their injection into the organism [26-28] confirm the idea, that bone marrow is a source of circulating tissue-committed morphogenic stem cells $[13,24]$. The vascular endothelium is renewed with the help of circulating CD133+ progenitor cells of bone marrow origin [29]. Even if primitive bone marrow cells do not transdifferentiate, as some suggest, but only fuse with target host cells or excrete of some cytokines and nutrients [30] they thus support the regeneration of target tissues. A steady-state of cell proliferation in different tissues of the body is supposed to be, maintained by T-lymphocytes too [31]. Most early memory lymphocytes, as well as mononuclear stem and progenitor cells penetrate through capillary walls into the interstitium of non-lymphoid tissues like the skin, muscle, liver, small and large intestine and the central nervous system to exert most of their protective and homeostatic activities under a noninflammatory steadystate conditions [32]. They sacrifice themselves in support of the lives of the surrounding cells. The TdT + prolymphocytes, $\gamma \delta$-T cells $(\mathrm{CD} 4-$ CD8-) [33] and CD3+CD31+CXCR4+ angiogenic T-lymphocytes [34] participate directly in tissue repair through the production of the growth factors, nutrients, and acceleration of the processes of angiogenesis. All these cells seem a trophocytes, feeding lymphocytes, rather than immunocytes, according to Fidler's prediction [35].

\section{Spontaneous cancer is likely self-tissue and rather feds by the host}

A candidate for a feeding system for cancer is hematopoiesis, which supports the viability of an organism as a whole by the mechanism more universal, than immunity [23]. The well-studied phenomenon of total aplasia of the thymus in the middle age shows the applicability of morphogenesis function of circulating cells to cancer supply. The event of thymus aplasia is accompanied by the dislocation of the T-cell production from the gland to the bone marrow, by the temporary decrease in the number of immature CD4+CD62L+, CD8+CD 122+ lymphocytes in the blood $[36,37]$ and by the temporary retardation of age-specific reduction of length of lymphocytes' telomeres [38]. The expected in this connection maximum of all chronic non-malignant illnesses at middle age confirmed for population of eight countries of Northern Europe [39]. The maximum of the non-malignant morbidity rate is registered at middle age for a restricted group $(n=14.448)$ of Chernobyl's clean-up workers too [36]. Moreover, a relative risk of complications of influenza (such as hospitalizations and/or deaths) increased from age 20 to age 49 , according to natural thymus functions involution, and then slowly declines again to age 60-69, as is shown for 43,545 adults populated Ontario state and aged $\geq 20$ [40]. To the contrary, the lowest rates of death and the highest 3-10 year survival of adult cancer patients correspond to the middle age region of around 50 years according to SEER database (Surveillance, Epidemiology, and End Results; National Cancer Institute, USA) [41-43]. The described infectious/ malignant age relation is not explainable by intensifying of cancer immunity, as raise of infectious morbidity contradicts to this. In contrast, a universal ability of primitive cells in blood to support the cellular renewal in many tissues of the organism is quite acceptable for the explanation of the mentioned relation. The temporary shortage of tissue renewal may reduce both tumor aggressiveness and a nonmalignant somatic resistance toward infection. Thus, well-established morphogenesis properties of circulating cells can be combined with real pathogenic processes, explaining some principal discrepancies at the level of populations.

\section{Blood supply is vital for tumor development but not its regression}

The rate of cancer progression depends obviously on microvessels density of the tumor tissue. The local regrowth a tumor after temporary arrest of its mitotic activity starts from the peripheral, most vascularized zones only, but not from central hypoxic ones with a deficit of immunocytes in them. The hypoxic conditions provoke the massive emigration of malignant cells to the new, more vascularized areas in the organism, provide the start of metastases and paralyze the effectiveness of chemotherapy [44]. The metastases appear only during the slow (quasi-linear) phase of the primary tumor growth, which replaces the previous fast (logarithmic) phase with highest microvessels density [45]. This sequence of events confirmed by a lack of hypoxia marker MCT4 expression in tumors of breast cancer patients with the high 10-year survival rate (mostly local development) and the high level of marker expression at the low survival rates (early spreading) [46]. Therefore, sufficient interaction of circulating blood with cancer cells promotes their local development and vice versa. Thus, a key to a local tumor proliferation is a feeding function of blood vessels even if they deliver supposed "protective" cells. The development of modern antiangiogenic therapy [4] supports this priority of blood supply for local growth of malignant tissue. In parallel, the CD133 hematopoietic stem cells are a universal angiogenic agent in non-malignant tissues [47].

\section{Hematopoiesis and tumor tissues}

There are no doubts today that similarity in collaboration between morphogenesis cells of the hematopoietic system and malignant tissues exists. CD133-positive cells found in the carcinomas of the liver, lung, colon, skin, prostate, nervous and muscular tissues are called as cancer stem cells (CSC) [48]. Nevertheless, cancer can be developed from CD133 - negative cells also [49]. Moreover, misleading intercellular transfer of a CD133 marker into a tumor cell is possible due to simple cellular fusion [50]. CD34+ stem cells migrate from the bone marrow into tumors of the lung, stomach, prostate, liver, and skin too. The increasing number of circulating primitive CD133+cells [51], as well as CD34 cells and young lymphocytes, is associated with a failing prognosis and survival of patients with cancer of the lung, ovary, colon, breast [35,52]. Thus, migration of morphogenesis cells or trophocytes into a tumor can support viability of malignant tissue via reutilization of debris [53,54-56], fusion with them [50,57], microvessels development $[14,17,58,59]$.

As early as last century Gutman M. with coauthors stated, that therapeutic myelosuppression may result at least in inhibition of host cell-induced tumor angiogenesis, which is not an immune process.

The sectional case of updating vascular endothelium by CD133+ endothelial precursors and angiogenic $\mathrm{T}$ lymphocytes (CD3+, CD31+, and CXCR4+) may be at least a quite acceptable example of such a morphogenesis mechanism. Angiogenesis of tumor, being a principal cause of its progression and more intensive than that in a histologically identical normal tissue, is the main target of antiangiogenic therapy [4]. The rate of capillary networks formation and local growth of tumors 
correlate directly with both CD133+ cells expression [14] and the expression of vascular endothelial growth factor C [60], which originates predominantly from hematopoietic stem cells and lymphocytes according Wartiovarra U. with colleagues [61]. The rise in the dead but not in viable CD45-CD31-CD146+ T-positive endothelial precursors in the tumor presence showed a highly significant, positive correlation with antiangiogenic therapy response and with patient benefits [62].

Depletion of so-called immune regulatory $\mathrm{T}$ cells results in growth delay and transient regression of experimental tumors [63]. It is remarkable that the number of typical $\mathrm{CD} 4+\mathrm{CD} 25+$ immune regulatory T-cells positively correlates with the number of CD133+CD34+ early endothelial progenitor cells [64]. Moreover, the CD25 is an early T-cell surface antigen, which coexists with TdT- antigen on young $\mathrm{T}$ cells in Pro-T2 / Rre-T1 stages of maturation [65]. The other regulatory T-cells presented by transitional stages of differentiation [66] depend quantitatively from a regenerative capacity of stem cells [67]. Some of them (double -negative CD3+CD4-CD8-) can be TdT-positive too [65], others have signs of incomplete maturity (CD62L) or signs of activated CD34+ hematopoietic progenitors (CXCR3, CD122) [24]. Thus, the family of immune "regulatory "cells can be identified not only as suppressors of tumor immunity but as morphogenesis providers supporting the tumor growth.

In both cases, the strategy of therapy demands their elimination. Hence, there is an alternative mechanism for indirect tumor growth control, which based on inhibition of uniform for both nonmalignant and malignant tissues physiological feeding system lymphocytopoiesis.

\section{Moderate mielosuppression inhibits infectious immunity and cancer activity, as thymus involution and aging do}

\section{Moderate mielosuppression provide indirect control of tumor growth}

Permitted inhibition of lymphopoiesis during conventional cytotoxic therapy [8] is a puzzle of anti-cancer immunity. The matter is that a therapy is only effective, if the poiesis is possible to produce enough lymphocytes to keep their level in blood near to physiological range and at low neutrophil / lymphocyte ratio (NLR). Such abnormalities like high NLR or lymphopenia before treatment are prognostically strong negative. The increasing NLR correlates with the severity of the clinical outcomes of many diseases $[68,69]$. Besides this, the number and function of hematopoietic stem cells (HSCs) causatively associates with overall organismal aging and longevity. The number of lymphoid progenitor cells dramatically decreases with age without malignancy [70,71], and the myeloid/lymphoid ratio of elderly HSC becomes 3-fold higher, then young one [72]. The well-known increase in malignancy by age reverses in the oldest cohort of patients. The incidence, mortality , and prevalence of a wide variety of cancer sites $(n=24)$ stop their increases at approximately 80 years of age, and then decline during the last 25 years to a natural age limit of 105 years [3]. During aging, the mean rank of death from infectious influenza and pneumonia (J09-J18) increases from 11 (at ages of 45 - 79 years) to 7 (at ages of 85 to $\geq 100$ years), manifesting as weakening of the immune system. However, the rank of death from malignant neoplasms (C00-C97) diminishes from 1 to 3 [73], reflecting their trophic dependence on lymphopoiesis. These population-based results correlate with age-dependent impairment of angiogenesis and cancer tumor growth in humans [74,75], and are consistent with in-phase changes of the presence of the CD133 marker in blood and the process progress of malignancy [76]. We consider this natural relief of malignancy as a prototype of cancer therapy.

The other puzzle of non-selective cytotoxic chemotherapy of cancer is that it cannot damage the tumor cells lethally, as the highdose, local radiotherapy does. According to the level of lymphopenia during the conventional treatment, its radiation equivalent is not more, than 2 - 3 Gy, which cannot be lethal for a healthy man yet. Then, systemic chemotherapy is unable to kill tumor cells fundamentally, as it demands a few dozen Gy. [77-80]. Otherwise, nonselective chemotherapy would be fatal to the organism as a whole. Beside this, a myelosuppressive action of modern combined chemotherapy is not the rare, random event, because $85 \%$ of main drugs are myelosupressive agents [81] including modern ones [82]. Hence the mechanism of chemotherapy supposed to be an indirect one, causing temporary disturbances of cellular reproduction [83]. Lymphopoiesis is a vulnerable system in mammals, and lymphopoietic reproductive capacity is the most amortizable among other physiological tissue systems in the thymus, BM, gastrointestinal tract, breast, ovary, skin, lung, kidney, liver, adrenal, adipose tissue, muscle, bone, and brain, which could all be responsible for the natural involution of the organism [84]. Nevertheless, the partial recovery of lymphocytopoiesis can be possible even after the number of non-lethally injured stem cells in bone marrow drops to 3-5\%. That is a reason for official permission the very deep lymphocytopenia induced by both local (selective) high dose radiotherapy and non-selective chemotherapy or wholebody cancer therapy [8]. This similarity points to the importance of temporary cellular deficiency in the blood for getting a positive clinical result. Subtotal or total body irradiation with doses 5-40 times lower than local high dose radiotherapy provoke nevertheless temporary weakening of the tumor growth accompanied by lymphocytopenia and by results comparable with chemotherapy $[35,85,86]$. The fast reduction of tumor growth in parallel with therapeutic inhibition of the regenerative status of bone marrow assumed by us as the result of either depletion of trophic prolymphocytes in circulation or redistribution them into non-malignant tissues for recovery their cells injured sublethally. Namely, reparation of very numerous non-lethal damages in the majority of non-malignant cells is the main reason for attraction feeding cells from a tumor on a competitive base, just as it can occur at non-selective cytotoxic chemotherapy or whole- body radiotherapy [42].

Thus, the lymphocytopenia and reparable injuries in non-malignant tissues during cytotoxic cancer treatment become a logical argument for temporary treatments benefit instead to be the contradiction to the idea of therapeutic stimulation of anti-tumor immunity. In this context, the common consequences of palliative cancer therapy will discuss in next sections.

\section{Hematopoiesis and probability of cancer therapy success}

\section{Probability of cancer therapy success in case of individual patient}

There is a little of discussion about the limitation of the natural lymphopoietic capacity of the organism along with life, diseases, and treatment, apart from well-known prognostic deterioration at declining universal of neutrophils /lymphocytes ratio (N/LR) for many diseases [68].

Results of modern therapy of advanced cancer often become disappointing. According to general immunological point of view, a fatal development of tumor happens either because of deception 
of defensive system by a surprisingly low number of malignant cells at the very beginning, or because of followed exhaustion of immune potency during the long struggle against the majority of abnormal cells. Then, an additional lymphocytopenia induced inevitably by conventional cytotoxic therapy looks harmful [8]. However, the same lymphocytopenia looks quite relevant if it to consider basing on morphogenic processes.

There are many reasons to divide the progress of cancer disease onto two phases at least [87]. Treatment usually continues until it has a chance to work but, in parallel, from cycle to cycle it exhausts regenerative capacity of lymphopoiesis, and induces serious complications, including incurability and a higher risk of death. People who are much older and have exhausted lymphopoiesis may not be able to tolerate intense treatment, which brings no benefit, despite its intensification [88].

Therefore, at phase 1, the growth of tumor forces the hematopoiesis to supply additional feeding cells. It is true, the higher lymphocytosis before cytotoxic treatment and more evident lymphocytopenia are after, the less mortality is $[71,78,79,89]$. In this phase, cytotoxic therapy interferes tropic supply of cancer tissue by course to course but depletes concomitantly sensitive lymphocytopoiesis until its complete exhaustion. Once injured by therapy, lymphocytopoiesis recovers spontaneously between courses and provides again cell renewing in privileged cancer tissues, bringing relapse of disease.

Eventually, over-production of stem cells in bone marrow, typical for phase 1, replaced by the weakened ( turbulent) stem cells genesis phase 2, which, in turn, finishes with irreversible total somatic exhaustion/cachexia incompatible with life [90]. The hematopoietic turbulence of CD34+cells content in blood at phase 2 is accompanied by synchronized fluctuations of monthly mortality of patients with advanced carcinomas during the final year of their life [71]. The found stem cells fluctuations in the blood are in agreement with replays of natural (asymmetric) type of bone marrow cells division on abnormal (symmetric) one in phase 2 [91].

As the turbulence provokes sooner or later a fatal deficit of the morphogenesis cells in somatic tissues, the chronic homeostatic imbalance between created and lost biomasses of the body has to follow. In spite of intensive treatment and unlimited food, cachexia affects nearly half of all cancer patients being the cause of one-third of cancer-specific deaths.

It is remarkable, that one of the attempts to cure cachexia bases on the replenish hematopoietic stem cells in blood as they significantly contribute to tissue regeneration [92]. Consequently, the deep pretreatment lymphocytopenia in phase 2 is a poor personal characteristic of the patient and predicts the failure of conventional cytotoxic therapy [93]. The unstable proliferation in bone marrow in phase 2 is a course of prognostic instabilities some signs related to hematopoiesis. Contrary to phase $1, \mathrm{CD} 133$ positive expression in advanced cholangiocarcinoma predicts a surprisingly favorable outcome of patients ( 14 months median survival), while negative CD133 expression correlates with poor prognosis (4 months median survival) [94]. This inversion reflects the general shortage of morphogenesis cells in the blood and tissues of terminal patients at the end of life with increased risk of death from common somatic frailty.

It is important to note, that this prognostic inversion compromises malignant origin of CD133+ cells called as cancer SC. Similarly, the preliminary exhausting of hematopoiesis by large field and high dose radiotherapy inverts expected mobilization of CD34+ host progenitor cells by G-CSF's injection to super-exhaustion the bone marrow reproductive capacity, and increases risk of death, chiefly because of common somatic disability [95]. The attempts to replenish the poiesis in phase 2 cachexia with low doses of growth factor are remarkable since hematopoietic stem cells in the blood significantly contribute to tissue regeneration [92]. Thus, phase 2 reflects a victory of a quasi-embryonic malignant tissue over non-malignant ones in unequal competition for exploit of a naturally limited morphogenesis resource of cancer host's hematopoiesis. The dividing of tumor's development on phase 1 and phase 2 explains why the therapeutic lymphocytopenia coexists with beneficial results at forced proliferative potency of bone marrow but later, at its exhaustion, becomes dangerous for patients life.

\section{Uncertainty of average results of therapy in group}

Such tests as survival and average life span predetermine by a distribution of the personal proliferative resources of the hematopoietic system among subjects inside the group before the action of injured factor [96]. Any real group always consists of patients with transitional characteristics of hematopoiesis between two, formally described above, phases 1 and 2. For the correct expectation of survival and average life span needs to know the ratio of patients with phase 1 and phase 2 in the untreated group. Most of the survivals curves are biexponential that confirm the mixt type of studied groups consisted of persons with poiesis in phases 1 and 2 . Considerable variability of individual life span in groups of cancer patients is persisting even if the group consists of members with uniform diagnosis and uniform treatment [87].

Variability of an average life span at treated cancer diseases covers range around 1-25 years independently from age at diagnosis [42] and is comparable with the variation of "ideal" natural aging, which occupies period 80-110 years old. Analysis of natural survival curves by age for countries with high social status has shown specific rectangularity of the curve, which arises due to the strongly $\approx 30$ fold increasing the exponential rate of death at the last $20-25$ years of life. [80,97]. Thus, the majority of untreated patients with malignant diseases were older, than their calendar age of diagnoses. Although their lifespan was increased by 5 - 10 years because of therapy, when diagnosed between 15 - 65 years of age, it will result in the concomitant loss of $55-5$ years of active natural longevity [80]. Those treated in phase 2 of poiesis had the live span of 1-2 years, but those in phase 2 lived 7-10 times longer [87].

The randomized data of the surprisingly lowest $(<3 \%)$ contribution of curative cytotoxic chemotherapy to 5 -year survival of adult cancer patients from USA and Australia provoked recently chemotherapy disappointment [98].

The low percentage of complete responses to chemotherapy confirmed the disappointment later [99]. These results seem regular in the light of practical incurability of patients who start the treatment in phase 2 of the reproductive resource of their lymphocytopoiesis, and their domination in studied cohorts. Even the mild stimulation of exhausted lymphopoiesis by natural growth factor leads to its deterioration [95] and no reason to expect stimulation phenomenon from cytotoxic drugs, originated from their historical ancestor in oncology - mustard gas. Thus, the curable part of the group/population of patients depends on the percentage of members with powerful lymphopoiesis in it, because of conventional cytotoxic therapy bases on the competitive principle restriction of the tumor's feeding with trophic lymphoid cells $[80,100]$ 
The principle advantage of competition therapy based on the redirection of the morphogenetic lymphocytes from tumor to the multitude of slightly injured host tissues is the preservation of a limited lymphopoietic reserve, in contrast with all other kinds of cytotoxic therapy followed by deep lymphocytopenia. But the level of optimal reparable injury of non-malignant tissues, its origin and volume in every personal case are in obscure yet. However, it is a perspective field for the lymphopoietic system reappraisal, which will overcome and reconcile a theoretical inconsistency not attract the attention of modern science aimed presumably at the molecular level.

\section{Phenomenon of spontaneous cancer regression is ex- ample of competitive tissues regeneration}

The disappearance of all or at least some relevant parameters of a soundly diagnosed malignant disease without any medical treatment or inadequate treatment for the resulting regression defines as spontaneous regression (SR). The pathophysiology to spontaneous resolution of cancer is not well understood and requires further study. It is a rare (1:60000 or 1:100000), but exciting event in oncology, which is seen sporadically in every type of cancer and nowadays there are no more doubts on the validity of the observation [101-106]. The known offered explanation of SR due to severe local infection (with streptococci, measles, viral hepatitis, herpes zoster or chickenpox during peritonitis, pneumonia, artificial graft versus processes), and even the so-called psychoneuroimmunological reactions is doubtful as it based on parallel activation of anti-cancer immunity. SR observed among the patients with HIV-compromised T-cell immunity $[107,108]$ and after an episode of myocardial infarction [106]. In rare cases, forced regeneration of non-malignant tissues restricts the vascularization processes in the residual tumor and results in further SR [109]. In most cases of well- documented SR are possible to see the concomitant surgical components in tissues aside tumor such as ample excision of abdominal wall, incomplete resection, thoracotomy, bypass surgery with intestine, bowel, hernia, followed by a second surgical exploration, postoperative fever, pneumonia, prolonged healing of postoperative wounds, and ctr. In all such situations the incomplete chronic regeneration of injured tissues is the real event which accompanies SR. Even extreme physiological conditions such as pregnancy can provoke temporary exhaustion of lymphocytopoiesis followed by spontaneous regression of a carcinoid tumor [110]. Therefore, SR, as well as the positive results of complementary medicine methods, deserve a more scientific systematic registry of cases and sophisticated scrutiny, because a deep understanding of such tumor control may lead to a new, unexpected, unusual therapeutic approach in oncology.

The simplest explanation of the SR phenomena for the cases of long-term tumor dormancy and exceptional treatment-related survival bases on the morphogenetic function of lymphocytes. Presently, there are no doubts that lymphocytes can promote cancer growth in their attempt to repair what they perceive as a wound or other tissue injuries including cancer itself [111]. The priority in morphogenic service belongs to cancer as an embryonic-like tissue. The priority realizes via redistribution the morphogenetic cells to the tumor and following bodyweight loss and cachexia. A competitive mechanism assumes the inhibition of trophic supply in the residual tumor during the concomitant wound healing after incomplete resection, reparation of non-malignant cells injured sublethally by cytotoxic agents, supply the enormously high fetus growth and other processes, which consume the naturally limited proliferating resource of lymphocytopoiesis of the host. The simple competitive scheme explains described cases of SR and some other obscure clinical phenomena such as the positive results of total body irradiation of cancer patients with low, non-tumoricidal doses as well, as cytotoxic chemotherapy at large [79], or radiation hormesis [96,112,113].

In light of the ability of sublethally injured non-malignant tissues to compete with the tumor for the regenerative resource of circulating feeding (trophic) cells of bone marrow origin, the possible mode of tumor control could look like a crazy fantasy. For example, it could be the bone fracture followed by long-term slight mechanical stretching of the broken ends to delay the knit-like structure, as used to be done for surgical lengthening of bone with the cosmetic aim. Some other mechanical provocations of morhogenesis are known for either restriction of tumor development [114] or for improvement feeding of liver graft inside the holistic system called homeostasis [28]. Accordingly, any artificial activity aside tumor without specific cytotoxic properties can indirectly control the growth of cancer via provoking renewing processes in non-malignant tissues. But the regular therapeutic benefit is possible presumably in conditional phase 1 of lymphopoiesis, as the drug treatment results in a tumor burden debulking matched with mild cachexia [115]. High resting energy expenditure in cancer patients due to hypermetabolism and repeated courses of cytotoxic treatment both increase the consumption of limited morphogenesis resource and exhausts it faster in comparing with physiological growth only. The cachexia in cancer has different grades [116] and is result of exhaustion of morphogenesis processes that confirmed by loss of body weight and lowest median of overall survival [117]. So, in phase 2 of lymphopoiesis exhaustion the successive competitive treatment becomes less probable, if not reversed to negative $[87,118]$. Pending further developments, we assume that the nature of the SR phenomenon is similar to the exhaustion of lymphocytopoiesis at successful conventional cytotoxic therapy in phase 1 of lymphocytopoiesis. However, the probability of SR registration is much lower because it arises presumably in phase 2 of lymphopoiesis when the probability of competitive mechanism realization is very low or questionable as well.

\section{Conclusion}

The comparing of clinical cancer features in alternative terms of immunity or morphogenesis leads to recognition of the trophic contribution of hematopoietic cells into tumor development. Replacement of the immune pathogenesis of cancer on a feeding one eliminates global discrepancies described in the introduction and elucidates the questions, why circulating cells of the host take part in the creation of microvessels of malignant tissue, ignoring their supposed allogenic, and how cancer may "deceive" the host. This alternative is in agreement with bone marrow's potency to produce circulating subsets, which are committed to supporting regenerative processes in both non-malignant and malignant tissues. As tumor progression consumes an extra -number of such circulating cells, the hematopoiesis of the host becomes more intensive first and exhausted secondly. Therapeutic myelosuppression is the cause for indirect retardation of tumor progression at early stages only but becomes a threat to life later. That is the reason for the adaptation of cytotoxic therapy for a personal clonogenic resource of the hematopoietic system of a patient.

\section{References}

1. Sakaguchi S (2005) Naturally arising Foxp3- expressing CD25+CD4+ regulatory $\mathrm{T}$ cells in immunological tolerance to self and non-self. Immunology 6: 345-352. [Crossref]

2. Ekka-Zochar A, Zitser-Gurevich Y, Mandel M, Weiss-Salz I, Nir Ba S, et al (2006) Graft survival and its determinants: a 3 year national experience with liver transplantation in Israel. Isr Med Assoc J 8: 400-405. [Crossref] 
3. Harding C, Pompei F, Wilson R (2012) Peak and decline in cancer incidence, mortality, and prevalence at old ages. Cancer 118: 1371-1386. [Crossref]

4. Heymoch J, Folkman J, Kalluri R (2010) Tumour angiogenesis. Cancer Medicine. $\left(8^{\text {th }}\right.$ edn). People's Medical Publishing House, USA: 148-169.

5. De Palma M, Biziato D, Petrova TV (2017) Microenvironmental regulation of tumour angiogenesis. Nat Rev Cancer 17: 457-474. [Crossref]

6. Kopjar N, Garaj-Vrhovac V, Kasuba V, Rozgaj R, Ramic S, et al. (2009) Assessment of genotoxic risks in Croatian health care workers occupationally exposed to cytotoxic drugs: a multi-biomarker approach. Int J Hyg Environ Health 212: 414-431. [Crossref]

7. Shuryak I, Hahnfeldt P, Hlatky L, Suchs RK, Brenner DJ (2009) A new view of radiation induced cancer: integrating short- and long-term processes. Part II: Second cancer risk estimation. Radiat Environ Biophys 48: 275-286. [Crossref]

8. https://ctep.cancer.gov/protocoldevelopment/electronic_applications/ctc.htm\#ctc_50

9. Garau MM, Calduch AL, López EC (2011) Radiobiology of the Acute Radiation Syndrome. Rep Pract Oncol Radiother 16: 123-130. [Crossref]

10. Shutko AN, Shatinina, NN, Lubotskaia LS, Ekimova LP (1981) Lymphocyte Trophic Function as a Potential Reserve in Improving Results of Tumor Radiotherapy. Med Radiol (Mosk) 26: 39-44. [Crossref]

11. Yu P, Fu YX (2006) Tumor-Infiltrating T Lymphocytes: Friends or Foes? Lab Invest 86: 231-245. [Crossref]

12. Ruffell B, De Nardo DG, Affara NI, Coussens LM (2010) Lymphocytes in Cancer Development: Polarization towards Pro-Tumor Immunity. Cytokine Growth Factor Rev 21: 3-10. [Crossref]

13. Drapeau C (2010) Cracking the Stem Cell Code: Demystifying the Most Dramatic Scientific Breakthrough of Our Times. Sutton Hart Press, Hillsboro.

14. Maltby S, Freeman S, Gold MJ, Baker JHE, Minchinton AI, et al. (2011) Opposing Roles for CD34 in B16 Melanoma Tumor Growth Alter Early Stage Vasculature and Late Stage Immune Cell Infiltration. PLoS One 6: e18160. [Crossref]

15. Rennert RC, Sorkin M, Gargand RK, Gurtner GC (2012) Stem Cell Recruitment after Injury: Lessons for Regenerative Medicine. Regen Med 7: 833-850. [Crossref]

16. Bruno A, Pagani A, Pulze L, Albini A, Dallaglio K, et al. (2014) Orchestration of angiogenesis by immune cells. Front Oncol 4: 131. [Crossref]

17. Zidlik V, Brychtova S, Uvirova M, Ziak D, Dvorackova, J (2015) The Changes of Angiogenesis and Immune Cell Infiltration in the Intra- and Peri-Tumoral Melanoma Microenvironment. Int J Mol Sci 16: 7876-7889. [Crossref]

18. Finkin S, Yuan D, Stein I, Taniguchi K, Weber A, et al. (2015) Ectopic Lymphoid Structures Function as Microniches for Tumor Progenitor Cells in Hepatocellular Carcinoma. Nat Immunol 16: 1235-1244. [Crossref]

19. Patman G (2015) Hepatocellular Carcinoma: Ectopic Lymphoid Structures Promote Carcinogenesis in the Liver. Nat Rev Gastroenterol Hepatol 12: 671. [Crossref]

20. Hevitt HB, Blake ER, Walder AS (1976) A critique of the evidence for active host defense against cancer based on personal studies of 27 mourn tumors of spontaneous origin. Br J Cancer 33: 249-2513. [Crossref]

21. Hewitt HB (1979) A critical examination of the foundations of immunotherapy for cancer. Clin Radiol 30: 361-369. [Crossref]

22. Chigira M, Arita S, Watanabe H (1993) Myth of tumor immunology (review). Int $J$ Oncol 3: 645-653. [Crossref]

23. Chigira M (1994) Self and nonself: duality of immune system. Med Hypotheses 43: 6-10. [Crossref]

24. Kucia M, Ratajczak J, Ratajczak MZ (2005) Bone marrow as a source of circulating CXCR4+ tissue-committed stem cells. Biol Cell 97: 133-146. [Crossref]

25. Stroo I, Stokman G, Teske GJ, Florquin S, Leemans JC (2009) Haematopoietic stem cell migration to the ischemic damaged kidney is not altered by manipulating the SDF1/CXCR4-axis. Nephrol Dial Transplant 24: 2082-2088. [Crossref]

26. Kolvenbach R, Kreissig C, Cagiannos C, Afifi R, Schmaltz E (2010) Intraoperative adjunctive stem cell treatment in patients with critical limb ischemia using a novel point-of-care device. Ann Vasc Surg 24: 367-372. [Crossref]

27. Shoutko AN, Gerasimova OA, Ekimova LP, Fedorov VA, Zherebtsov FK, et al. (2016) Long-Term Activation of Circulating Liver-Committed Mononuclear Cells after OLT. Jacobs J Regenerative Med: 1 .
28. Shoutko AN, Gerasimova OA, Fedorov VA, Zherebtsov FK (2019) Non-Invasive Vibration-Stress of the CirrhoticLiver of Patients Waiting for TransplantationInduces of Circulating CD133+ Stem Lymphocytes Committed Phenotypically toward the Liver. OJBIPHY 9: 155-168.

29. Wassmann S, Werner N, Czech T, Nickenig G (2006) Improvement of endothelial function by systemic transfusion of vascular progenitor cells. Circ Res 99: e74-83. [Crossref]

30. Burchfield JS, Dimmeler S (2008) Role of paracrine factors in stem and progenitor cell mediated cardiac repair and tissue fibrosis. Fibrogenesis Tissue Repair 1: 1-11. [Crossref]

31. Strick-Marchand H, Masse GX, Weiss MC, Di Santo JP (2008) Lymphocytes support oval cell dependent liver regeneration. J Immunol 181: 2764-2771. [Crossref]

32. Halin C, Mora JR, Sumen C, von Andrian UH (2005) In vivo imaging of lymphocyte trafficking. Annu Rev Cell Dev Biol 21: 581-603. [Crossref]

33. Roullet M, Gheith SMF, Mauger J, Junkins-Hopkins JM, Choi JK (2009) Percentage of \{gamma\} \{delta\} $\mathrm{T}$ cells in panniculitis by paraffin immunohistochemical analysis. $\mathrm{Am}$ J Clin Pathol 13: 1820-1826. [Crossref]

34. Hur J, Yang H-M, Yoon C-H, Lee C-S, Park K-W, et al. (2007) Identification of a nove role of $\mathrm{T}$ cells in postnatal vasculogenesis. Characterisation of endothelial progenitor cell colonies. Circulation 116: 1671-1682. [Crossref]

35. Shoutko A, Shatinina N (1998) Chronic Cancer Could It Be? Coherence Int J Integrated Med 2: 36-40.

36. Karamullin MA, Sosyukin AE, Shoutko AN, Nedoborski KV, Ekimova LP (2006) Possible role of determined by age changes of the lymphopoiesis in the long-term morbidity levels of Chernobyl' clean-up workers. Medical Radiology And Radiation Safety 4: 42-51.

37. Rifa'i M, Kawamoto Y, Nakashima I, Suzuki H (2004) Essential roles of CD8+CD122+ regulatory T cells in the maintenance of T cell homeostasis. J Exp Med 200: 1123-1134 [Crossref]

38. Aubert G, Lansdorp PM (2008) Telomeres and aging. Physiol Rev 88: 557-579. [Crossref]

39. Layte R, Nolan A, Nolan B, Van Ourti T (2005) Health and morbidity by age and socioeconomic characteristic. European Network of Economic Policy Research Institutes, ENEPRI, report 15: 1-119.

40. Ontario Agency for Health Protection and Promotion (Public Health Ontario) (2017) The relationship between influenza medical risk factors and age. Toronto, ON: Queen's Printer for Ontario.

41. Shoutko AN, Akushevich I, Ekimova LP, Karamullin MA (2010) Variation of Death Risk Among Cancer Patients. Vis-a-Vis Individualized Therapy. Voprosi Onkologii 56: 430-434. [Crossref]

42. Shutko AN, Akushevich IV, Ekimova LP, Mus VF, Sokurenko VP, et al. (2013) The Mechanism of The Antitumor Effect of Total/Subtotal Radiotherapy In Nontumoricidal Doses of Radiation. Vopr Onkol 59: 475-482. [Crossref]

43. Shoutko AN, Ekimova LP (2014) The impact of middle age on the viability of patients with nonmalignant and malignant diseases. Cancer Res J 2: 114-120.

44. Keunen O, Johansson M, Oudin A, Sanzey M, Rahim SA, et al. (2011) Anti-VEGF treatment reduces blood supply and increases tumor cell invasion in glioblastoma. Proc Natl Acad Sci U S A 108: 3749-3754. [Crossref]

45. Yamaura H, Matsuzawa T (1979) Tumour Regrowth after Irradiation. Int J Radian Biology Related Studies in Physics, Chemistry and Medicine 35: 201-219.

46. Witkiewicz AK, Whitaker-Menezes D, Dasgupta A, Philp NJ, Lin Z, et al. (2012) Using the "reverse Warburg effect" to identify high-risk breast cancer patients. Cell Cycle 11: 1108-1117. [Crossref]

47. Ratajczak J, Kucia M, Mierzejewska K, Marlicz W, Pietrzkowski Z, et al. (2013) Paracrine Proangiopoietic Effects of Human UmbilicalCord Blood-Derived Purified CD133+ Cells-Implications for Stem Cell Therapies in Regenerative Medicine. Stem Cells Dev 22: 422-430. [Crossref]

48. Walter D, Satheesha S, Albrecht P, Bornhauser BC, D'Alessandro V, et al. (2011) CD133 positive embryonal rhabdomyosarcoma stem-like cell population is enriched in rhabdospheres. PLOS ONE 6: e19506. [Crossref]

49. Shmelkov SV, Butler JM, Hooper AT, Hormigo A, Kushner J, et al. (2008) CD133 expression is not restricted to stem cells, and both CD133+ and CD133-metastatic colon cancer cells initiate tumours. J Clin Invest 118: 2111-2120. [Crossref] 
50. Gast CE, Silk AD, Zarour L, Riegler L, Burkhart JG, et al. (2018) Cell fusion potentiates tumor heterogeneity and reveals circulating hybrid cells that correlate with stage and survival. Sci Adv 4: eaat 7828. [Crossref]

51. Goon PKY, Lip GYH, Stonelake PS, Blann AD (2009) Circulating endothelial cells and circulating progenitor cells in breast cancer: relationship to endothelial damage/ dysfunction/apoptosis, clinicopathologic factors, and the Nottingham prognostic index. Neoplasia 11: 771-779. [Crossref]

52. Zhang J, Guo X, Chang DY, Rosen DG, Mercado-Uribe I, et al. (2012) CD133 expression associated with poor prognosis in ovarian cancer. Mod Pathol 25: 456-464. [Crossref]

53. Shutko AN, Shatinina NN, Rakitianskaia IA (1983) Role of terminal deoxyribonucleotidyl transferase in stimulating lymphocyte DNA synthesis as affected by PHA. Cytology 25: 1212

54. Labi V, Erlacher M (2015) How cell death shapes cancer. Cell Death Dis 6: e1675. [Crossref]

55. Muir A, VanderHeiden MG (2018) The nutrient environment affects therapy. Science 360: 962-963. [Crossref]

56. Sulciner ML, Serhan CN, Gilligan MM, Mudge D, Chang J, 1 et al. (2018) Resolvins suppress tumor growth and enhancecancer therapy. J Exp Med 215: 115-140. [Crossref]

57. Hernández JM, Podbilewicz B (2017) The hallmarks of cell-cell fusion. Development 144: 4481-4495. [Crossref]

58. Carvalho MI, Pires I, Dias M, Prada J, Gregório H, et al. (2015) Intratumoral CD3+ T-lymphocytesImmunoexpression and Its Association With c-kit, Angiogenesis, and Overall Survivalin Malignant Canine Mammary Tumor. Anal Cell Pathol (Amst) 6: 920409. [Crossref]

59. Mao Y, Qu Q, Chen X, Huang O, Wu J, et al. (2016) The Prognostic Value of TumorInfiltratingLymphocytes in Breast Cancer: A Systematic Review and Meta-Analysis. PLoSONE 11: e152500. [Crossref]

60. Maeda S, Shinchi H, Kurahara H, Mataki Y, Maemura K, et al. (2008) CD133 expression is correlated with lymph node metastasis and vascular endothelial growth factor-C expression in pancreatic cancer. Br J Cancer 98: 1389-1397. [Crossref]

61. Wartiovaara U, Salven P, Mikkola H, Lassila R, Kaukonen J, et al. (1998) Peripheral Blood Platelets Express VEGF-C and VEGFwhich Are Released during Platelet Activation. Thromb Haemost 80: 171-175. [Crossref]

62. Starlinger P, Brugger P, Reiter C, Schauer D, Sommerfeldt S, et al. (2011) Discrimination between circulating endothelial cells and blood cell populations with overlapping phenotype reveals distinct regulation and predictive potential in cancer therapy. Neoplasia 13: 980-990. [Crossref]

63. Baba J, Watanabe S, Saida Y, Tanaka T, Miyabayashi T, et al. (2012) Depletion of radio-resistant regulatory $\mathrm{T}$ cells enhances antitumor immunity during recovery from lymphopenia. Blood 120: 2417-2427. [Crossref]

64. Schwartzenberg S, Mor A, Luboshits G, Planer D, Deutsch V, et al. (2005) Association Between Circulating Early Endothelial Progenitors and CD4+CD25+Regulatory T Cells: A Possible Cross-talk between Immunity and Angiogenesis? Am J Immunol 1: 143-147.

65. Rehg JE, Bush D, Ward JM (2012) The utility of immunohistochemistry for the identification of hematopoietic and lymphoid cells in normal tissues and interpretation of proliferative and inflammatory lesions of mice and rats. Toxicol Pathol 40: 345-374. [Crossref]

66. Shoutko A, Karamullin M, Ekimova L, Shoumski I, Phyodorov V (2005) Latent time of generation of different lymphocytes subsets in blood of Chernobyl clean workers. Book of Abstracts of 34th Annual meeting of European Society for Radiation Biology, University of Leicester, UK, pp: 166-167. [Crossref]

67. Shoutko AN, Gerasimova OA, Ekimova LP, Zherebtsov FK, Granov AM (2015) Features of Subpopulation Composition of Blood Lymphocytes in Recipients within the First Month After Liver. Bulletin of Transplantology and Artificial Organs 17: 6873.

68. Templeton AJ, McNamara MG, Šeruga B, Vera-Badillo FE, Aneja P, et al . (2014) Prognostic Role of Neutrophil-to-Lymphocyte Ratio in Solid Tumors: A Systematic Review and Meta-Analysis. J Natl Cancer Inst 106: dju124.

69. Cho U, Park HS, Im SY, Yoo CY, Jung JH, et al. (2018) Prognostic Value of Systemic InflammatoryMarkers and Development of a Nomogram in Breast Cancer. PLoS ONE 13: e0200936 [Crossref]
70. Van Zant G, Liang Y (2012) Concise Review: Hematopoietic Stem Cell Aging, Life Span, and Transplantation. Stem Cells Transl Med 1: 651-657. [Crossref]

71. Shoutko A, Ekimova L, Mus V, Sokurenko V (2012) Fluctuations of CD34 cells number inblood of cancer patients during final year of life. Med Heal Sci J 13: 7-13. [Crossref]

72. Pang WW, Price EA, Sahoo D, Beerman I, Maloney WJ, et al. (2011) Humanbone marrow hematopoietic stem cells are increasedin frequency and myeloid-biased withage. Proc Natl Acad Sci USA 108: 20012-20017. [Crossref]

73. https://www.cdc.gov/nchs/data/dvs/lcwk/lcwk1_hr_2016.pdf

74. Rivard A, Fabre J-E, Silver M, Chen D, Murohara Tet al. (1999) Age-Dependent Impairment of Angiogenesis. Circulation 99: 111-120. [Crossref]

75. Weedon-Fekjær H, Lindqvis BH, Vatten LJ, Aalen OO, Tretli S (2008) Breast Cancer Tumor Growth Estimated through Mammography Screening Data. Breast Cancer Res 10: R41. [Crossref]

76. Natale G, Bocci G (2017) Tumor Dormancy, Angiogenesis and MetronomicChemotherapy. Tumor Dormancy and Recurrence, Humana Press, Springer Int. Publ., Cham, pp: 31-50. [Crossref]

77. Barnett GC, West CM, Dunning AM, Elliott RM, Coles CE, et al. (2009) Norma Tissue Reactions to Radiotherapy: Towards Tailoring Treatment Dose by Genotype. Nat Rev Cancer 9: 134-142. [Crossref]

78. Shoutko AN, Yurkova LE, Borodulya KS, Ekimova LP (2015) Lymphocytopenia and Cytotoxic Therapy in Patients with Advanced Ovarian Cancer. Cancer Res J 3: 47-51.

79. Shoutko AN, Yurkova LE, Borodulya KS, Ekimova LP (2016) Protracted Half-Body Irradiation Instead of Chemotherapy: Life Span and Lymphocytopenia in Relapsed Ovarian Cancer. Int J Tumot Ther 5: 1-7.

80. Shoutko AN (2019) Overview of Hematopoietic Stem Cells in Systemic Cancer Treatment, Aging, Pregnancy, and Radiation Hormesis. Advances in Molecular Images (AMI) 9: 19-42. [Crossref]

81. Liesveld JL, Rubin P, Constine LS (2014) Hematopoietic System. In: Rubin P, Constine LS, Marks LB, Eds. Adverse Late Effects of Cancer Treatment 2: Normal Tissue Specific Sites and Systems. Springer Verlag, Heidelberg: 623-656.

82. Deligne C, Milcent B, Josseaume N, Teillaud JL, Sibéril S (2017) Impact of Depleting Therapeutic Monoclonal Antibodies on the Host Adaptive Immunity: A Bonus or a Malus? Front Immunol 8: 950. [Crossref]

83. Malhotra V, Perry MC (2003) Classical chemotherapy: mechanisms, toxicities and the therapeutic window. Cancer Biol Ther 2: 2-4. [Crossref]

84. da Costa JP, Vitorino R, Silva GM, Vogel C, Duarte AC, et al. (2016) A Synopsis on Aging-Theories, Mechanisms and Future Prospects. Ageing Res Rev 29: 90-112. [Crossref]

85. Yurkova LE, Shoutko AN (2013) Assesment of therapeutic possibilities of system radiotherapy as a component of combined treatment for advanced ovarian cancer. $\mathrm{Vopr}$ Onkol 59: 479-482. [Crossref]

86. Scott BR (2008) Low-dose-radiation stimulated natural chemical and biological protection against lung cancer. Dose Response 6: 299-318. [Crossref]

87. Shoutko AN, Mus VF (2018) Potential of Hematopoietic Stem Cells and Mitotic Activity in Peripheral Lymphocytes to Predict Life Expectancy of Patients with Metastatic Non-Small Cell Lung Cancer after Conventional Therapy. Advances in Molecular Imaging (AMI) 8: 25-37.

88. Yoon J-H, Kim H-J, Min W-S (2017) Comparison of the Effects of EarlyIntensified Induction Chemotherapy and Standard 3+7 Chemotherapy in Adult Patients with Acute Myeloid Leukemia. Blood Res 52: 174-183. [Crossref]

89. Shoutko AN, Ekimova LP, Sokurenko VP, Matyurin KS, Karamullin MA (2011) Alternative changes of lymphocytopoiesis of cancer patients are retained during radiation therapy. Book of Abstracts of 14th International congress of Radiation Research ICRR, Warsaw, Poland, pp: 163.

90. Fliedner TM, Graessle DH (2008) Haematopoietic cell renewal systems: mechanisms of coping and failing after chronic exposure to ionising radiation. Radiat Environ Biophys 47: 63-69. [Crossref]

91. Storm K, Kurre P (2013) Ex-vivo expansion of stem cells: inspiration from a highly specialized biologic niche. ASH. The Hematologist: 21:12-1241. 
92. Coletti D, Belli L, Adamo S (2006) Cachexia: novel perspectives for an old syndrome. Basic Appl Myol 16: 131-139. [Crossref]

93. Ray-Coquard R, Cropet C, Van Glabbeke M, Sebban C, Le Cesne A, et al. (2009) Lymphopenia as a prognostic factor for overall survival in advanced carcinomas, sarcomas, and lymphomas. Cancer Res 69: 5383-5391. [Crossref]

94. Zhu L, Zhou LK, Xue M, Yan HM, Liu J, et al. (2009) Factors impacting yield of CD34(+) cells from healthy donors mobilized with rhG-CSF. Zhongguo Shi Yan Xue Ye Xue Za Zhi 17: 1541-1545. [Crossref]

95. Pape H, Orth K, Heese A, Heyll A, Kobbe G, et al. (2006) G-CSF during large field radiotherapy reduces bone marrow recovery capacity. Eur J Med Res 11: 322-328. [Crossref]

96. Shoutko AN, Ekimova LP (2014) Abnormal tissue proliferation and life span variability inchronically irradiated dogs. Radiat Environ Biophys 53: 65-72. [Crossref]

97. https://www.ons.gov.uk/peoplepopulationandcommunity/populationandmigration/

98. Morgan G, Ward R, Barton M (2004) The contribution of cytotoxic chemotherapy to 5-year survival in adult malignancies. Clin Oncol (R Coll Radiol) 16: 549-560. [Crossref]

99. Ashdown ML, Robinson AP, Yatomi-Clarke SL, AshdownML, Allison A, et al. (2015) Chemotherapy for Late-Stage Cancer Patients: Meta-Analysis of Complete Response Rates. F1000Res 4: 232. [Crossref]

100. Shoutko AN, Yurkova LE, Borodulya KS, Ekimova LP, Matyurin KS (2017) Competitive principal of tumor control in radiological clinic. Radiol Diagn Imaging 1: 1-2.

101. Kuwal A, Chauhan N, Dutt N, Elhence P, Advani M et al. J (2019) Spontaneous Partial Regression of a Carcinoid Tumor: Radiology May Not Capture the Real Picture. Turk Thorac 20: 153-156. [Crossref]

102. Ooi KH, Cheo T, Ting Soon GS, Leong CN (2018) Spontaneous regression of locally advanced nonsmall cell lung cancer. Medicine 97: 31. [Crossref]

103. Roelofsen T, Wefers C, Gorris MAJ, Textor JC, Massuger LFAG, at al. (2018) Spontaneous Regression of Ovarian Carcinoma After Septic Peritonitis; A Unique Case Report. Front Oncol 8: 562. [Crossref]

104. Vernon LF (2018) William Bradley Coley, MD, and the phenomenon of spontaneous regression. Immunotargets Ther 7: 29-34. [Crossref]

105. Ariza-Prota M, Martínez C, Casan P (2018) Spontaneous regression of metastatic squamous cell lung cancer. Clin Case Rep 6: 995-998. [Crossref]
106. Chin KM, Chan CY, Lee SY (2018) Spontaneous regression of pancreatic cancer: A case report and literaturere view. Int J Surg Case Rep 42: 55-59. [Crossref]

107. Dickman MJ, Bresser P, Noorduyn LA, Reiss P (1992) Spontaneous regression of Ki-positive T-cell non-Hodgkin's lymphoma in a patients with HIV-infection. $\mathrm{Br} J$ Haematol 82: 477-478. [Crossref]

108. Karand AB, Jaffar A, Lands RH (1992) Spontaneous regression of acquired immune deficiency syndrome-related high grade extrandal non-Hodgkin's lymphoma. Cancer 69: 1856-1857. [Crossref]

109. Smith RA (1971) Cure of lung cancer from incomplete surgical resection. Br Med $J$ 2: 563-565. [Crossref]

110. Sewpaul A, Bargiela D, James A, Johnson SJ, French JJ (2014) Hindawi Publishing Corporation. Case Reports in Endocrinology: 481823.

111. Jessy T (2011) Immunity over inability: The spontaneous regression of cancer. $J$ Nat Sci Biol Med 2: 43-49. [Crossref]

112. Shoutko AN, Ekimova LP (2017) The Effects of Tissue Regenerative Status on Hormesis in Dogs Irradiated during Their Lifespan. Open Journal of Biophysics 7: 101-115.

113. Calabrese EJ, Mattson MP (2017) How Does Hormesis Impact Biology, Toxicology, and Medicine? NPJ. Aging and Mechanisms of Disease: 3.

114. Berrueta L, Bergholz J, Munoz D, Muskaj I, Badger GJ, et al. (2018) Stretching Reduces Tumor Growth in a Mouse Breast Cancer Model. Scientific Reports 8: 7864.

115. De Lerma Barbaro A (2015) The complex liaison between cachexia and tumor burden. Oncol Rep: 1635-1649. [Crossref]

116. Vagnildhaug OM, Blum D, Wilcock A, Fayers P, Strasser F, et al. (2017) The applicability of a weight loss grading system in cancer cachexia: a longitudinal analysis. J Cachexia Sarcopenia Muscle 8: 789-797. [Crossref]

117. Vanhoutte G, van de Wiel M, Wouters K, Sels M, Bartolomeeussen L, et al. (2016) Cachexia in cancer: what is in the definition? BMJ Open Gastroenterol 3: e000097. [Crossref]

118. Shoutko AN, Gerasimova OA, Ekimova LP, Zherebtsov FK, Mus VF , et al. (2017) Lymphocyte Reproductive Activity Normalized to Numbers of Hematopoietic Stem Cells in Blood and Rate of Death in Fatal Diseases. Int J Genetics Genomics 5: 54-62.

Copyright: (C2019 Shoutko AN. This is an open-access article distributed under the terms of the Creative Commons Attribution License, which permits unrestricted use, distribution, and reproduction in any medium, provided the original author and source are credited. 